\title{
The results of monitoring of hydroimpulsive disintegration of outburst-prone coal seams using ZUA-98 system
}

\author{
Vasyl Zberovskyi ${ }^{1, *}$, Kostiantyn Sofiiskyi ${ }^{1}$, Rishard Stasevych ${ }^{1}$, Artem Pazynych ${ }^{1}$, Jan \\ Pinka $^{2}$, and Marina Sidorova ${ }^{2}$ \\ ${ }^{1}$ Institute of Geotechnical Mechanics named by N. Poljakov of National Academy of Sciences of \\ Ukraine, 49005, Dnipro, Simferopolska Str., 2a, Ukraine \\ ${ }^{2}$ Technical University of Kosice, 04200, Kosice, Letna 9, Slovakia
}

\begin{abstract}
The paper represents the results of monitoring and evaluation of the efficiency of hydroimpulsive disintegration of outburst-prone coal seams in the stopes of development mine workings using a system of sound detecting facilities. Methods of acoustic emission control have been considered as well as the monitoring tasks to evaluate rock mass conditions before the procedure and after it inclusive of the results of sound accompaniment of hydraulic disintegration of the coal seam. It has been determined that the higher concentration of stresses within the rock mass is, the more efficient action of high frequency self-oscillations of cavitation transmitter is on both the fissuring and changes in gas-dynamic state of the coal seam. It has been recommended to apply a mode of impulsive fluid pumping under the conditions where coal seam is in the stress-strain state.
\end{abstract}

\section{Introduction}

A problem of prevention from sudden coal and gas outbursts still remains the most complicated and topical one. Control and efficiency of the standard method of hydraulic disintegration of outburst-prone coal seams are performed as follows: pressure drop of the fluid pumped into the coal seam; initial velocity of gas emission from the test holes; and frequency response characteristics of the sound signal being recorded and transmitted by a system of seismic acoustic signal transmission (SAST) (ZUA-98) [1]. However, the measures are not sufficient to prevent from gasdynamic phenomena while driving workings under the complicated mining and geological conditions. Moreover, parameters of hydraulic disintegration process and changes in stress-strain state (SSS) of rock mass in front of a stope, helping develop a safe area of coal extraction, are out of control.

To improve mining safety, a method of hydroimpulsive disintegration (HID) has been developed for outburst-prone coal seams [2-11]. Contrary to the standard techniques for HID process monitoring, a method of monitoring of the intensity of operation schedules by means of a system of sound detecting facilities (SDF) has been used [1]. Using the control of acoustic emission (AE) parameters, the method helps to run the "action - rock mass -

*Corresponding author: igtmdep16@gmail.com 
response" process arising within the rock mass during coal disintegration. Following conditions are taken into consideration during hydraulic disintegration using the ZUA-98 system [12]:

- AE arises within the rock mass areas where local stresses excess local boundary of coal hardness;

- $\mathrm{AE}$ is a response to the imbalance of available stresses within the rock mass, i.e. to mining operations;

- the rock mass is controlled remotely. None of the conditions of the basic operation schedule is violated.

Use of ZUA-98 system in the process of experiments aimed at HID of seams is innovation in the practice of hydraulic disintegration of outburst-prone coal seams. Thus, objective is to analyze monitoring results of hydraulic disintegration process obtained with the help of the ZUA-98 system.

\section{Methods}

Underground instrumental measurements and statistical processing of results of the measurements have been applied.

The following methods have been used in the process of the research: experimental methods of the phenomenon of regular explosion cavitation; analytical methods of engineering analysis of dynamic parameters as well as characteristics of self-oscillations of a fluid pressure; methods of mining and experimental activities etc. [11].

The results of HID process monitoring have been analyzed in accordance with the diagnostic technique using the ZUA-98 system [12] making it possible to probe any rock mass while drilling either control holes or technological wells and while pumping a fluid into a coal seam.

Distance between the hole or well drilling is one meter. Activity profile of AE signals is developed in the form of the specific amount $(N)$ of the AE impulses per a meter of the wells. The profiles and drilling schedule along the well length help to evaluate changes in stresses deep in the rock mass in front of the mine working stope. Hydraulic disintegration process is evaluated depending upon changes in amplitude-frequency spectrum (AFS) of AE signals.

According to "Regularities..." [1], mine seismoacoustic forecast service uses software application package for automatic recording of AE signal as well as its amplitude $(A)$ in terms of decibel scale of sound level against the backdrop of acoustic accompaniment of operation schedule displayed by a monitor of an operator of the ZUA system.

\section{Results and discussion}

Underground experiments have been carried out in four stopes of development mine workings using $k_{2}{ }^{l}$ and $i_{3}{ }^{1}$ seams under the conditions of structural subdivision (SS) Shakhtoupravlinnia Molodohvardiiske (Krasnodonvuhillia PJSC). Consider the results in terms of HID of coal seam $k_{2}{ }^{l}$ in a stope of $33^{\text {rd }}$ eastern conveyor mine working (CMW) of $617 \mathrm{~m}$ level [11].

The underground investigations have involved eight cycles of hydraulic disintegration in the standard methodology and seven cycles in the HID methodology. Mining operations within the stopes of the development mine workings have been performed in accordance with the standard operation schedule of hydraulic disintegration [1]. Pumping device SPA and a mechanism for hydroimpulsive action with a generator of cavitation self-oscillations of a fluid pressure GO-2.5 have been used for the fluid pumping [2]. Figure 1 explains 
arrangement of the wells and geophone in terms of $33^{\text {rd }} \mathrm{CMW}$ of seam $k_{2}{ }^{l}$ of $617 \mathrm{~m}$ of SS Shakhtoupravlinnia Molodohvardiiske (Krasnodonvuhillia PJSC).
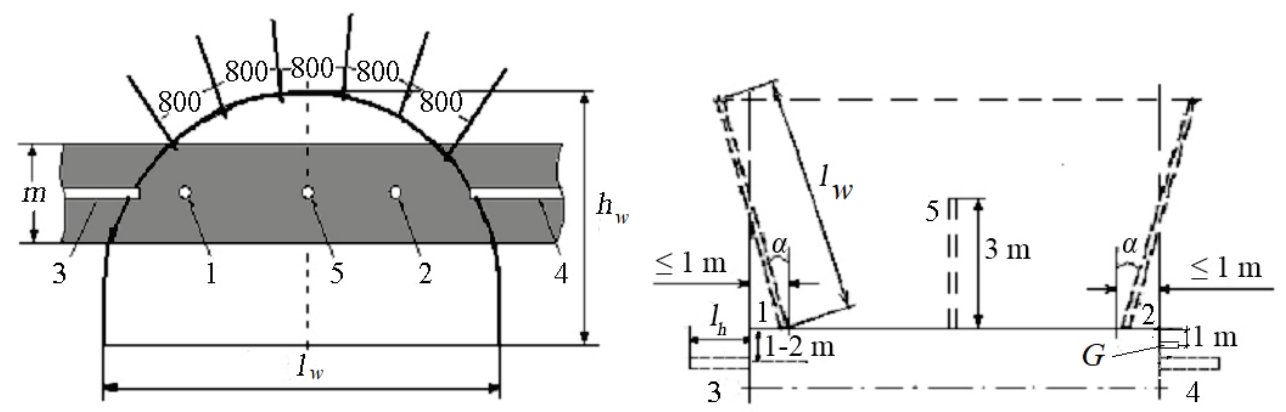

Fig. 1. Arrangement of the wells and geophone in terms of $33^{\text {rd }} \mathrm{CMW}$ [11]: 1, 2 - technological wells; $3,4,5$ - control holes; $l_{w}$ - well length, $\mathrm{m} ; l_{h}$ - borehole length, $\mathrm{m} ; \alpha$ - shaft angle of the well towards the rock mass; $G-\mathrm{ZUA}-98$ geophone.

KSP-32 coal shearer drives a mine working. Parameters of the mine working are as follows: height is $h_{w}=3.7 \mathrm{~m}$; width is $l_{w}=5.2 \mathrm{~m}$; and seam thickness is $m=1.6 \mathrm{~m}$. Support of the mine working is represented by the combined frame anchoring. Parameters of the technological wells are: drilling depth is $l_{w}=6.0 \mathrm{~m}$; hermetization well is $l_{g}=4.0 \mathrm{~m}$; and filtration share of the well is $l_{f}=2.0 \mathrm{~m}$. The geophone is installed at $0.2 \mathrm{~m}$ depth within the coal seam at $1.0 \mathrm{~m}$ distance from the mine working stope.

Research of HID process of the seam starts from the estimation of the rock mass SSS in front of the mine working stope. While deepening of the technological wells into the coal seam, changes in SSS have been determined within each drilling interval according to the number of the recorder AE signals (Fig. 2). A curve, connecting the number of marks of AE impulses, characterizes changes in the SSS of the rock mass for the space of five meters from the de-stressed area to the rock mass depth.

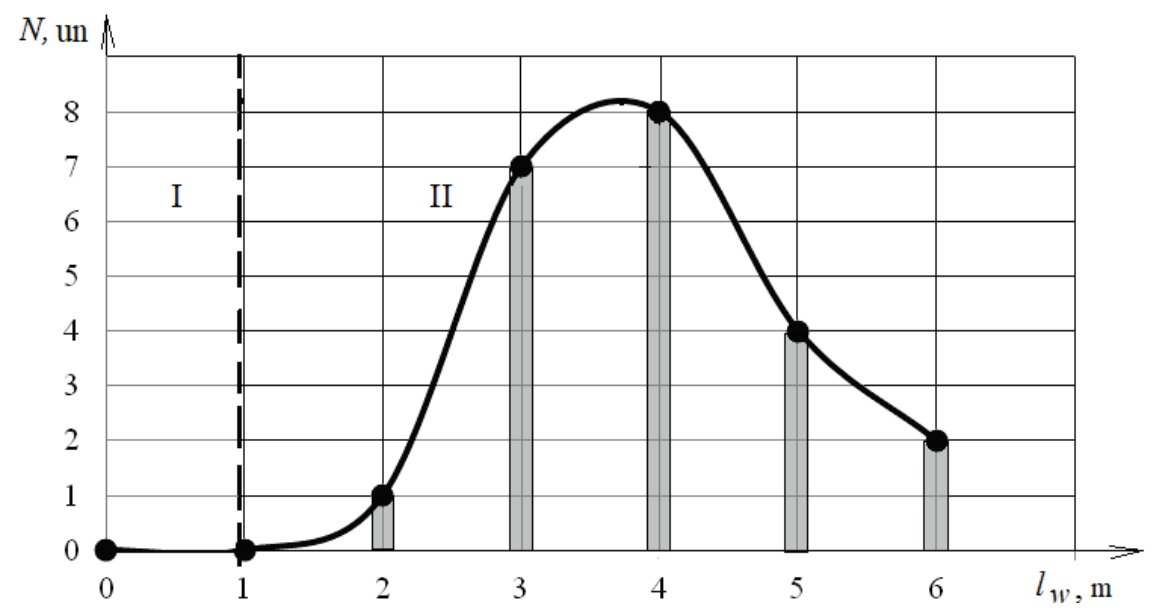

Fig. 2. AE activity of the rock mass in the process of technological well drilling: I - de-stressed area; and II - area of changes in stresses under the effect of rock pressure.

For the first time ever, the results have helped to determine that if frame anchoring is applied, then stresses, arising in front of a development mine working, start their increase at $1.0 \mathrm{~m}$ distance achieving their maximum at $3.5-3.8 \mathrm{~m}$ distance from the stope. Thus, hermetization area of a technological well should not be less than $4.0 \mathrm{~m}$ providing reliable sealing as well as the decreased fluid leakage from a filtration share of the well into the 
mined-out area. AE level drops down almost to a static one $(\gamma H)$ at $6.0 \mathrm{~m}$ distance from the mine working stope meaning that SSS of the rock mass reduces. The research has helped to substantiate the parameters of technological wells in terms of which hydroimpulsive effect is the most productive one.

Advantages of HID of coal seam and its reliability have been identified while comparing the results of instrumental measurements of control parameters of the efficiency of techniques [1] obtained in terms of static (i.e. standard) mode and impulse (i.e. HID) modes of a fluid pumping (Table 1) [11].

Table 1. Results of the research of hydraulic seam disintegration [11].

\begin{tabular}{|c|c|c|c|c|}
\hline Pumping mode & $\begin{array}{c}\text { Pumping pressure, } \\
\text { MPa }\end{array}$ & $\begin{array}{c}\text { Pumping period, } \\
\text { min }\end{array}$ & $\begin{array}{c}\text { Fluid volume, } \\
\mathrm{m}^{3}\end{array}$ & Fluid loss, $1 / \mathrm{t}$ \\
\hline static & $14.0-18.0$ & 36.2 & 1.42 & 19.5 \\
\hline impulsive & $13.0-14.0$ & 9.2 & 0.52 & 7.0 \\
\hline \multicolumn{2}{|c|}{ Ratio of the results } & $74.6 \%$ & $63.4 \%$ & $64.1 \%$ \\
\hline
\end{tabular}

Analysis of the instrumental measurements has shown that relative to the standard method, fluid loss decreases by more than $60 \%$ if HID is applied; during a pumping period, it is four times less. The results have supported the expediency of HID of coal seam $k_{2}^{l}$ use under the conditions.

Consider monitoring results of coal seam $k_{2}{ }^{l}$ disintegration in a model of impulse fluid pumping (ILP) within the stress-strained area, and within the de-stressed area (Fig. 3, 4).

Figure 3 demonstrates patterns of waveforms of sound accompaniment of HID of coal seam $k_{2}^{l}$ processes recorded in the process of a fluid pumping into wells 1 and 2 (Fig. 1).

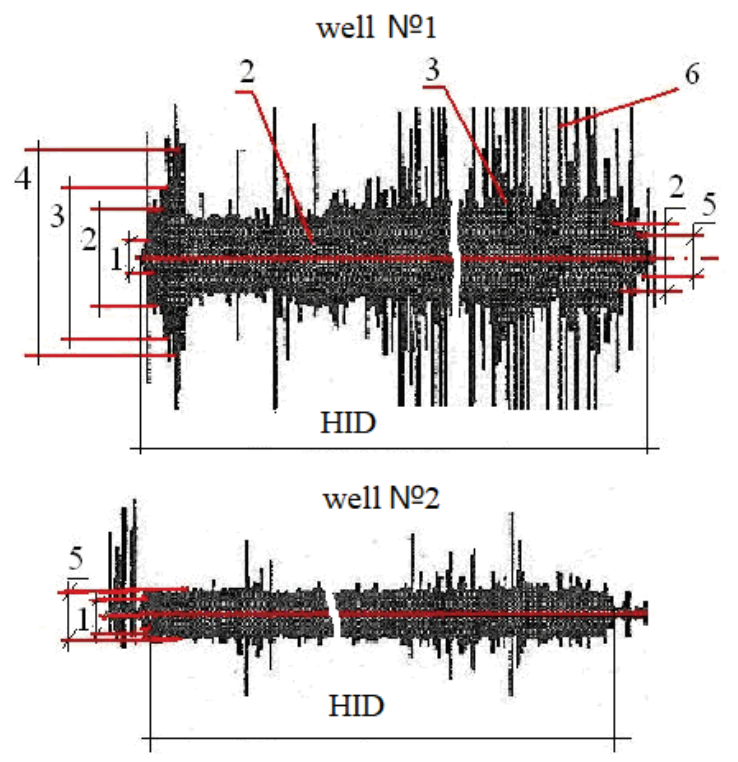

Fig. 3. Control results of sound accompaniment of hydroimpulsive disintegration process: 1 - level of acoustic signal of the pumping plant; $2-4-$ levels of acoustic signal within a working range of GO-2.5 generator; 5 - level of acoustic signal of a non-working range of the generator; $6-\mathrm{AE}$ of fissuring.

Relative to the afflux pressure variation within a well, analysis of the recorded $\mathrm{AE}$ signals during a fluid pumping has helped to determine the periods corresponding to different operation modes of GO-2.5. Comparison of the results with amplitude-frequency 
characteristic (AFC) of GO-2.5 generator in terms of different afflux pressures [11] has made it possible to identify both working and non-working generator modes in the wells according to changes in self-oscillation frequency. Operation mode of a generator (Fig. 3) is characterized by such levels acoustic signal $(2-4)$ when the effect of hydrodynamic parameters results in fissuring around the well. If AE of fissuring is not available (6) then level of acoustic signals of non-working range corresponds to the generator performance (5).

Consider operation modes of GO-2.5 within the wells in terms of AFS signals determined with the help of the application programs for automatic monitoring of sound accompaniment of level of AE signals $(\mathrm{dB})$ in the form of amplitude logarithm $(\lg A)$ and its impulses (Fig. 4).

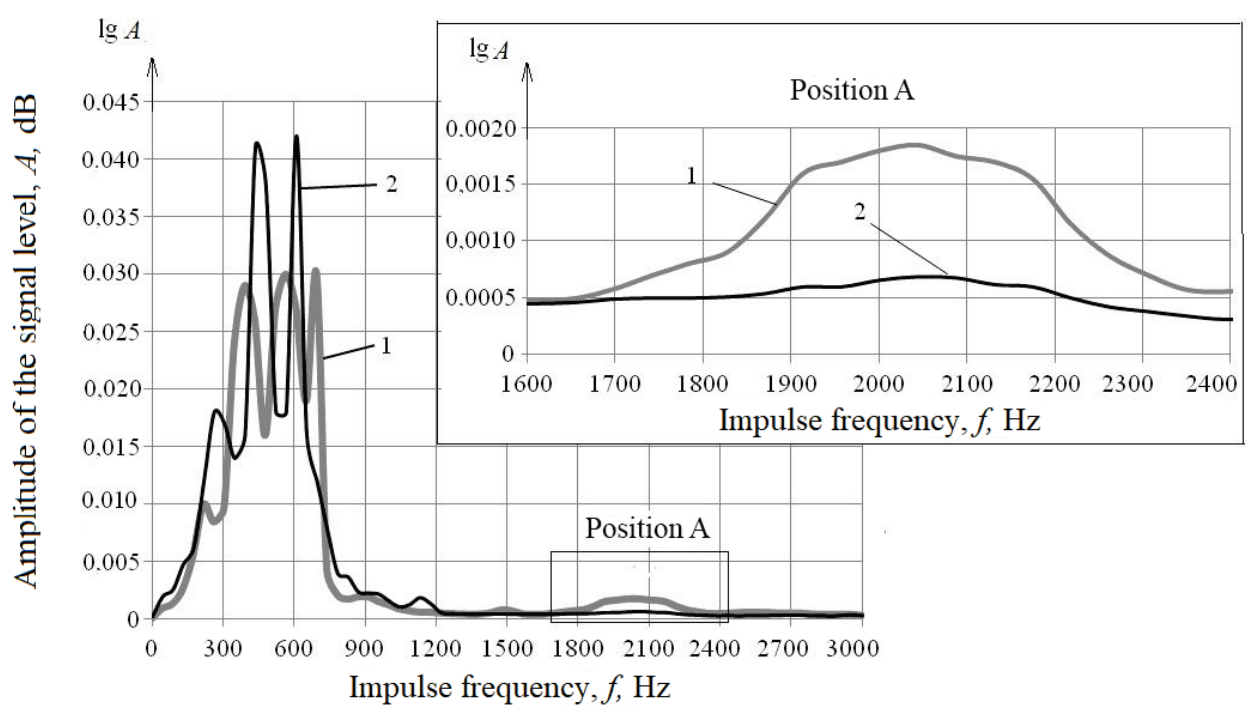

Fig. 4. Amplitude-frequency spectra of sound accompaniment of seam hydroimpulsive disintegration through wells 1 and 2: 1 - well 1; and 2-well 2.

It is understood from the figure, that AFS components of AE signals are recorded within a broad frequency range (i.e. $100 \mathrm{~Hz}$ to $3000 \mathrm{~Hz}$ ). Consequently, the sound accompaniment of HID process of a seam makes it possible to identify both fissuring progress within the coal seam and changes in performance of the generator. For the first time, the results have helped to consider AFS of high frequency self-oscillations of fluid pressure generated industrially by GO-2.5.

Low-frequency oscillations (i.e. up to $150 \mathrm{~Hz}$ ), resulting from the electrical noise, are not considered. Certain share of frequencies (up to $800 \mathrm{~Hz}$ ) is connected with the secondary oscillations as well as with changes in the rock mass SSS. Other components of the monitoring signal, corresponding to range of frequencies exceeding $900 \mathrm{~Hz}$, depend upon the self-oscillations generated by GO-2.5.

Consider monitoring results of the development of AFS parameters of sound accompaniment of HID of a coal seam in terms of wells 1 and 2 (Fig. 4). As for the well 1 (curve 1), components of AE signal involve broad range of the secondary oscillation of the coal seam $(300 \mathrm{~Hz}$ to $700 \mathrm{~Hz})$, changes in its stress state, and intensive fissuring.

Impulses of self-oscillations of GO-2,5 generator are recorded within $900-2400 \mathrm{~Hz}$. Operation mode of the generator (Position A, Fig. 4) consists of three frequency ranges (i.e. $1650-1900 \mathrm{~Hz}, 1900-2200 \mathrm{~Hz}$, and $2200-2350 \mathrm{~Hz}$ ) corresponding to $2-4$ levels of acoustic signal (Fig. 3).

As for well 2 (curve 2), frequency range of components of AE signal of the rock mass 
decreases down to $400-650 \mathrm{~Hz}$ since intensive fissuring is not available. Generator performance is recorded within the range of $1900-2200 \mathrm{~Hz}$. AFS level of acoustic signal corresponds to non-working level of the generator operation (Fig. 3). It means that the well is within the disturbed rock mass; fluid is filtered freely to the coal seam through fractures since affluent within a filtration share is not developed.

Hence, under the conditions of the stressed rock mass, high-frequency spectrum component depends upon the impulses generated by GO-2.5. In this context, the higher stress concentration within the rock mass is, the fuller and broader the spectrum of its components is. If HID is applied in terms of well 2, none of the components of a highfrequency spectrum with high energy level is available. Thus, the rock mass is de-stressed.

Therefore, the analysis of the results of changes in AFS parameters of AE components helps to conclude that if HID of coal seams is applied then energy of impulses of fluid pressure is materialized in the form of intensive fissuring. Ultrasound oscillations, propagating within the fluid around filtration share of a well, are transformed into secondary oscillations of the stressed coal seam. Recording of the oscillations with the help of ZUA-98 system has helped to determine source-rock mass-source reaction as well as the effect of dynamic parameters of cavitation fluid flow on the changes in SSS of the rock mass.

Following stage of the research involves analysis of the control results of the rock mass SSS and identifies of the areas of its changes in front of a mine working stope after HID of coal seam. The research [11] has determined that at $6.0 \mathrm{~m}$ distance from the mine working stope (i.e. down to the well drilling depth), AE impulses are not available. The results have helped to evaluate effect of hydroimpulsive action on the coal rock mass, define the destressed area where coal shearer may operate safely. At the same time, changes in the rock mass SSS in front of the mine working stope have not been analyzed.

Carry out the analysis of the results of the AE obtained while drilling an exploratory well after HID of coal seam (Fig. 5).

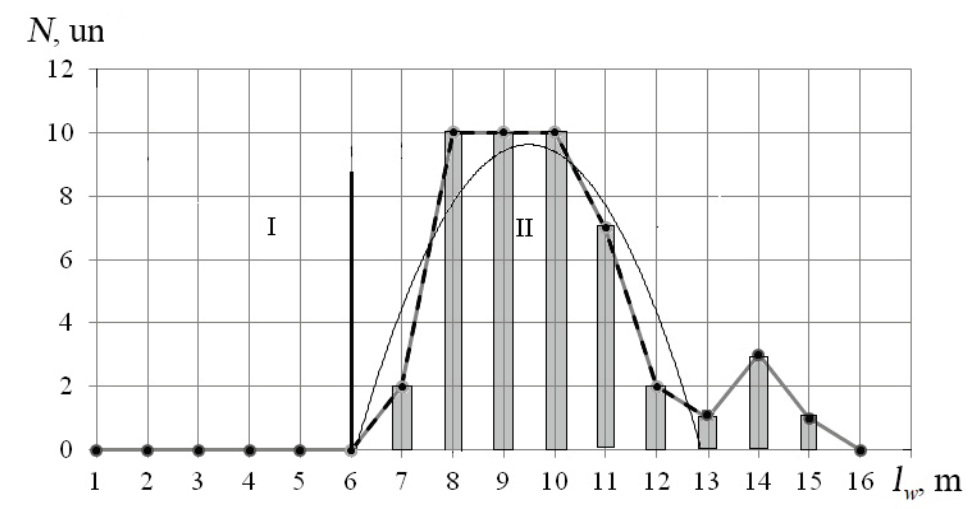

Fig. 5. Control results of the de-stressed area after HID of the coal seam: I - de-stressed area; and II area of changes in stresses under the effect of HID, and rock pressure.

The Figure demonstrates the determined de-stressed area - I where extraction by means of coal shearer is a safe process and area II where stress redistribution processes take place. $\mathrm{AE}$ activity profiles along the well length make it possible to evaluate stress changes within the rock mass relative to the de-stressed area I. Most likely, area of the HID of coal seam effect is formed within the rock mass at $6.0-13 \mathrm{~m}$ distance in front of the mine working stope. The area is characterized by dependence

$$
N=-0.833 l_{w}^{2}+15.81 l_{w}-65.35, \quad R^{2}=0.85,
$$


where $N$ is the number of AE impulses within one-meter interval, un.; $l_{w}$ is the well drilling depth, $\mathrm{m}$; and $R^{2}$ is determination coefficient.

Further, at the distance of up to $16 \mathrm{~m}$, area of rock pressure effect is formed. Hence, behind the $6.0 \mathrm{~m}$ dangerous area, redistribution processes of the rock mass SSS takes place over 10 meters. Comparison of the results with the results of stress progress before HID use (Fig. 2) shows that their redistribution area experiences its twofold increase (i.e. from 5 meters to 10 meters). In this context, maximum intensity of AE impulses increases from 8 units to 10 units within one-meter interval. It means that quite larger area of the rocks effects stress redistribution within the seam in front of a mine working after hydroimpulsive action. Thus, dimensions of safe extraction by means of a coal shearer should be specified with the help of a probe drilling or assumed as those being equal to the well length. Control results of hydroimpulsive disintegration by means of APSS-1 system support reliability of the research [10].

\section{Conclusions}

Analysis of the research results concerning HID of outburst-prone coal seam as well as changes in its conditions by means of ZUA-98 system has helped to conclude the following.

1. Acoustic emission, arising within the rock mass in the process of seam HID, is a response to imbalance of stresses, available in it characterizing fissuring process, and a process of changes in the rock mass SSS under the effect of fluid pressure generated by GO-2.5. The abovementioned helps to determine the "source-rock mass-source" response; to control operation mode of the generator; and to evaluate changes in SSS of the rock mass in time, i.e. before hydraulic disintegration and after it.

2. For the first time, AFS of high frequency self-oscillations of fluid pressure, generated by GO-2.5, have been recorded industrially. It has been determined that energy variations within AFS of sound AE accompaniment are recorded in a broad frequency range, i.e. from 100 to $3000 \mathrm{~Hz}$. Signal components within up to $800 \mathrm{~Hz}$ frequency range have made it possible to evaluate changes in the rock mass SSS; and more than $900 \mathrm{~Hz}$ frequency range has helped to determine level of acoustic signal of working range of GO-2.5 generator.

3. Expediency to use HID for outburst-prone coal seam is characterized by the lack of AE impulses within the area of safe coal extraction formed in front of a stope of a development mine working. Dimensions of the area should be specified with the help of a probe drilling or assumed as those being equal to the well length.

The research has made it possible to identify interrelation of "source - rock mass source" system and to solve a complex problem of the control over SSS of the outburstprone rock mass. Moreover, safe area for coal shearer operation in the process of mine working driving has been identified.

\section{References}

1. SOU 10.1.001740088-2005 (2005). Pravila vedeniia gornykh rabot na plastakh, sklonnykh $k$ gazodinamicheskim yavleniiam. Kyiv: Minugleprom Ukrainy

2. Vasyliev, L.M., Zhulai, Yu.O., Zberovskyi, V.V., Moiseienko, P.Yu., Trokhymets, M.Ya. (2009) Prystrii dlia hidroimpulsnoho vplyvu na vuhilnyi plast. Patent No 87038, Ukraine

3. Zberovskyi, V.V. (2008) Increasing the level of labor protection and mining safety by hydro-pulse impact on coal seams. Geotekhnicheskaia mekhanika [Geo-technical Mechanics], (74), 112-11 
4. Zberovskyi, V.V., Kostandov, Yu. A. (2011) The limiting state of outburst coal seams during their hydraulic loosening, taking into account the shear resistance of coal. Zbirnyk naukovykh prats NHU, 36(2), 36-43

5. Y. Zhulay, V. Zberovskyi, A. Angelovskii, I. Chugunkov, (2012) Hydrodynamic cavitation in energy-saving technological processes of mining sector (CRC Press/Balkema: EN Leiden, The Netherlands, 2012)

6. Zberovskyi, V.V., Zhulai, Yu.O., Vasyliev, L.M., Nikiforov, A.V., Kolchyn, H.I., Angelovskii, O.A., Chugunkov, I.F., Niskevich, O.M. (2012) Method of hydro pulse loosening of coal seams. Patent No 73023, Ukraine

7. Zberovskyi, V.V. (2017) Evaluation of the effectiveness of hydroimpulse effects on a coal seam by acoustic control methods. Geotekhnicheskaia mekhanika [Geo-technical Mechanics], (132), 74-84

8. V. Zberovskyi, O. Bubnova, K. Babii. Specifics of hydro-loosening of coal seams with account of rocks displacement parameters. E3S Web of Conferences, Ukrainian School of Mining Engineering, 60 (2018). https://doi.org/10.1051/e3sconf/20186000025

9. V. Zberovskyi. Control of the mud pulse method the loosening of coal layers by amplitude-frequency recommendation of acoustic signal by the APSS-1 system. E3S Web of Conferences, International Conference Essays of Mining Science and Practice, 109 (2019). https://doi.org/10.1051/e3sconf/201910900122

10. V. Zberovskyi, Yu. Zhulai, S. Mirnui. Evaluation of the cavitation generator efficiency in the hydro impulsive loosening of a coal-bed. E3S Web of Conferences, International Conference Essays of Mining Science and Practice, 109 (2019). https://doi.org/10.1051/e3sconf/201910900123

11. Zberovskyi, V.V. (2019) Rozvytok naukovo-tekhnichnykh osnov hidroimpulsnoyi dii na vykydonebezpechni vuhilni plasty. Avtoreferat dysertastii doctora nauk. Dnipro. IGTM, NAS of Ukraine

12. Deglin, B.M., Melkonian, A.A. (2008) Sound-absorbing equipment of the new generation - "ZUA-98-06". Gornyy informatsionno-analiticheskii byulleten, (10), 260262 